\title{
Versatality of Mandibular Premolar Extraction Forcep
}

\author{
Dr. Sneha Ginimav ${ }^{1}$, Dr. Manjunath Rai $^{2}$ \\ ${ }^{I}$ (Bds, Mds. Reader, Department Of Oral And Maxillofacial Surgery, Hkdet's College And Hospital.Humnabad, \\ Karnataka, India.) \\ ${ }^{2}$ (Bds, Mds, Mosrcs (Edinburg, Uk), Llm, Pgdmle, Professor And Head Of The Department ,Department Of \\ Oral And Maxillofacial Surgery ,A J Shetty Institute Of Dental Sciences , Mangalore, Karnataka, India)
}

\begin{abstract}
Several extraction techniques exist for extraction of upper premolar teeth, but proper selection of an appropriate instrument and technique requires understanding of the impact of manipulating the basic principles of extraction for individual cases. We recommend the below mentioned technique for extraction of upper premolar teeth, hence making extraction a doctor and patient friendly procedure.
\end{abstract}

Keywords: extraction, forceps, premolar

\section{Introduction}

Premolar is the most common teeth to be extracted as a part of therapeutic extraction in orthodontics. If the first procedure, which is extraction of premolar, is stressful and cumbersome to the patient, it might lead to demoralising the patient to take up further treatment with ease or might end up loosing confidence in his dentist. There are no set rules where certain procedures could be followed in order to obtain certain results. However this is not possible with the variables we encounter in our everyday practices. In our desire to obtain the utmost for our patients, we are prone to become too idealistic and forget the practical. A comprehensive management of any tooth extraction should aim at achieving high quality, satisfactory and fearless treatment procedure for the patient. Hence, new technique for extraction of maxillary premolars has been advocated below.

\section{Surgical Technique}

The chair is adjusted with the patient supine and the surgeon seated on a mobile chair capable of moving in an arc about the patients head. The surgeon usually sits behind the patient at 70 to 80 degrees angle and faces the same side as that of patient for upper right quadrant premolar extraction and at 20 to 30 degrees facing the patient for upper left quadrant premolar extraction Only one pattern of lower right - angled, British type premolar forcep is necessary for extraction of premolars in bilateral upper and lower quadrant. Lower premolar forceps are designed so that the beaks are angled with their handles at roughly $90^{\circ}$ from their blades and therefore the handles sit in the axial plane perpendicular to the maxillary dental arch. This allows the optimum position of the operator's hand for both power application and control. And also muscles are less prone to fatigue. The extractions are performed using the basic principles as in standing dentistry ${ }^{[1,2,3]}$.

Bone in the region of the maxillary teeth is quite commonly of the porous cancellous variety, with tissue paper thin bone over apices of maxillary teeth. ${ }^{[4]}$ Some slight modification of the supporting hand is necessary when working on the upper jaw . For extraction of right upper premolar, we used palm up pinch grasp technique with index finger on palatal side and thumb on buccal side and palm facing towards the head end of the patient. We used conventional pinch grasp technique for left upper premolar extraction. Forceps blades were applied with an apical pressure and aligned parallel with the long axis of the tooth for extraction and hence gave maximum support and in turn aided in even distribution of forces applied to the root. The relatively short blades engaged the tooth root and relatively long handle offered a large mechanical advantage in gripping and moving the tooth. The potential to apply substantial forces also increased. Therefore the tooth was not pulled out as done with conventional upper forceps but was rather luxated by giving mild buccal and palatal movements and then rolled out buccally in clockwise direction for premolars on the right upper quadrant and anticlockwise direction for premolars on the left upper quadrant after considering the various preoperative assessment parameters given in the TABLE.

Table: Checklist for Modified Extraction Technique

\begin{tabular}{|l|l|}
\hline Preoperative Assessment & Intraoperative Assessment \\
\hline Morphology Of The Crown & Appropriate Patient Positioning \\
\hline Morphology Of The Roots & Appropriate Operator Positioning \\
\hline $\begin{array}{l}\text { Density Of The Bone Surrounding } \\
\text { The Teeth }\end{array}$ & Accessibility By Adequate Tissue Reflection \\
\hline $\begin{array}{l}\text { Relationship Of Tooth To Adjacent } \\
\text { Teeth }\end{array}$ & $\begin{array}{l}\text { Appropriate Forceps With Slender Beaks So That They } \\
\text { Extend Into Periodontal Spaces, Maintain A Three }\end{array}$ \\
\hline
\end{tabular}




\begin{tabular}{|l|l|}
\hline & $\begin{array}{l}\text { Point Contact With The Tooth And Provide } \\
\text { Accessibility. }\end{array}$ \\
\hline $\begin{array}{l}\text { Relationship Of Tooth To } \\
\text { Important Adjacent Anatomical } \\
\text { Structures }\end{array}$ & $\begin{array}{l}\text { Use Finger To Guide The Forceps In The Right } \\
\text { Direction }\end{array}$ \\
\hline $\begin{array}{l}\text { Presence Of Any Pathology Of The } \\
\text { Tooth }\end{array}$ & Appropriate Placement Of The Beaks Of The Forceps \\
\hline $\begin{array}{l}\text { Presence Of Any Pathology Of } \\
\text { Bone Surrounding The Teeth }\end{array}$ & Use Of Controlled Force \\
\hline Adequate Mouth Opening & Adequate Hemostasis \\
\hline
\end{tabular}

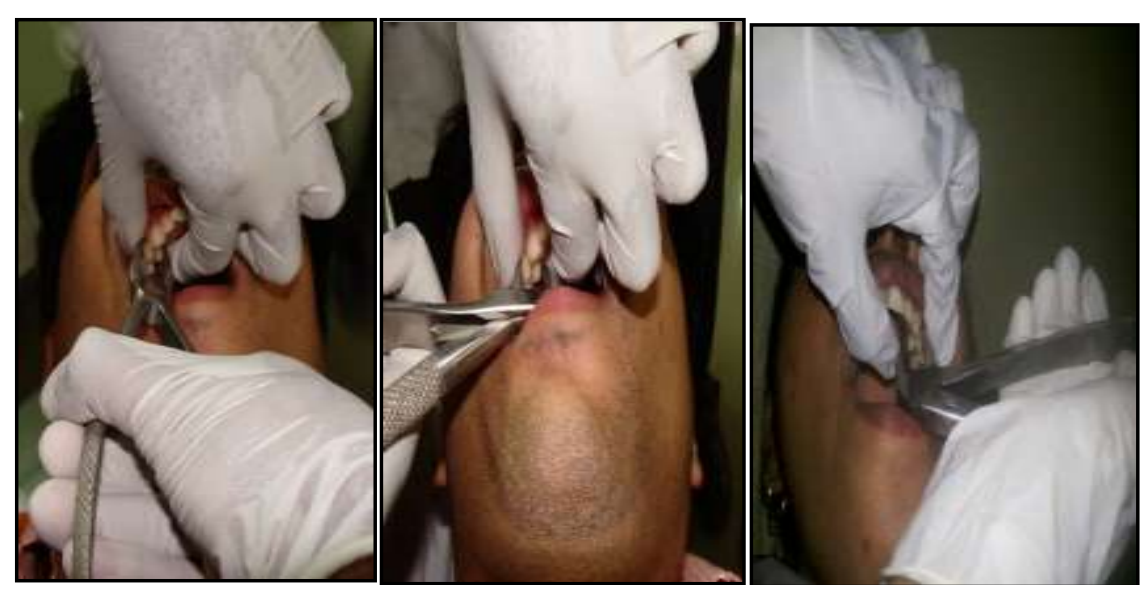

Fig 1 Conventional technique Fig2 Modified technique Fig 3 Modified technique for right upper premolar for left upper premolar

\section{Conclusion}

Advantages of modified technique are it lowers down the apprehensiveness of patient because forceps is away from direct vision of patient, can be performed in full sight of the operator, increased accessibility with minimal retraction of the soft tissues and reduced tissue trauma, less chances of breakage of root, limited mouth opening sufficient to extract the teeth, greatly saves operative and anaesthesia time, resulting in less postoperative stress and morbidity, For visiting consultants, the number of instruments carried to clinics is minimized.

It must be emphasized that there are hazards in operating on a supine patient as displaced teeth, roots or filling may fall back into the pharynx and the dental surgeon must take adequate steps to prevent this by getting the conscious patient to cooperate by turning his head well to one side during the operation. Further the assistant should have high power suction and a suitable instrument immediately available for grasping any displaced object. We must try to determine where idealism and realism part company. It is up to us to decide which are the best procedures to follow in order to attain our objectives.

\section{References}

[1]. Paul D. Robinson, Tooth Extraction: A practical guide (Varghese Publishing Company, Bristol : J. Wright, 2000)

[2]. Geoffrey L Howe.The extraction of Teeth(Varghese Publishing Company, Bristol : J. Wright, 1980)

[3]. J.R.Moore, G.V.Gillbe ,Principles of Oral Surgery ( Manchester, Manchester University Press, 1991)

[4]. Stanley F Malamed: Handbook of Local Anaesthesia( Missouri, Elsevier Mosby, 2004) 